\title{
Symptom burden and life challenges reported by adult chordoma patients and their caregivers
}

\author{
Paula H. Song ${ }^{1} \cdot$ Hadi Beyhaghi $^{1} \cdot$ Josh Sommer $^{2} \cdot$ Antonia V. Bennett $^{1}$
}

Accepted: 3 March 2017 / Published online: 17 March 2017

(C) The Author(s) 2017. This article is published with open access at Springerlink.com

\begin{abstract}
Purpose This study aims to characterize the symptom burden and life challenges that chordoma patients and their caregivers experience.

Methods In this cross-sectional study, we analyzed data from the Chordoma Foundation online community survey conducted in 2014. Frequency counts and percentages were calculated to determine the prevalence of self-reported symptoms and life challenges in the sample. We used Fisher's exact test to compare self-reported symptoms among subgroups with different disease status, tumor locations, and treatments received.

Results Among the survey participants, 358 identified themselves as chordoma patients and 202 as caregivers. The majority of the patients were over 45 years (72\%), male (56\%), educated beyond high school degree (87\%), and from North America (77\%). Skull base was the most prevalent tumor location (40\%). Chronic pain (35\%) was the most commonly reported symptom followed by depression or severe anxiety (32\%) and chronic fatigue (31\%). Among
\end{abstract}

Parts of this paper were presented in an abstract and poster forms at the 2016 International Chordoma Research Workshop on July 2016, in Boston.

Electronic supplementary material The online version of this article (doi:10.1007/s11136-017-1544-2) contains supplementary material, which is available to authorized users.

Paula H. Song

psong@unc.edu

1 Department of Health Policy and Management, The University of North Carolina at Chapel Hill, 1105A McGavran-Greenberg Hall, CB \#7411, Chapel Hill, NC 27599-7411, USA

2 Chordoma Foundation, Durham, NC, USA patients, the most commonly reported challenges included delayed care (37\%), long-term disability (33\%), and confusion or unanswered questions about chordoma (28\%). For caregivers, grief (55\%), delayed diagnosis (47\%), and difficulty helping the patient cope with his or her disease (45\%) were most common.

Conclusions Our study findings suggest a high symptom burden and life challenges among chordoma patients and their caregivers. This study provides preliminary, limited estimates of the prevalence of a wide range of selfreported symptoms and challenges that will inform the assessment of patient-reported outcomes in future clinical trials and help clinicians better manage chordoma patients' symptoms.

Keywords Chordoma - Symptom burden - Patientreported outcomes $\cdot$ Quality of life

\section{Introduction}

Chordoma is a rare bone cancer that accounts for $1-4 \%$ of all bone malignancies [1]. Chordoma is a highly morbid and potentially fatal disease that involves complex medical decisions, and the low incidence of chordoma creates challenges for tailoring care. Chordoma tumors are thought to be derived from notochord remnants that may persist anywhere along the axial skeleton [1,2]. Chordomas are generally slow growing, chemotherapy-, and radiotherapyresistant tumors that are locally invasive [1].

Population-based studies using the Surveillance, Epidemiology, and End Results (SEER) database estimate the age-adjusted incidence of all chordoma cases to be 0.08 to 0.089 per 100,000 . Chordoma is more common in men and the incidence is highest among 50-60 years of age [1-4]. 
Chordoma is less frequent among patients younger than 40 years and rarely affects children and adolescents (less than $5 \%$ of all chordoma cases) [1]. The anatomic distribution of chordomas is almost equal among the skull base (32\%), mobile spine (33\%), and sacrum (29\%) [1] Chordoma accounts for over $50 \%$ of primary sacral tumors [1] and less than $1 \%$ of all intracranial neoplasms [2].

Most studies estimate the survival of chordoma patients using data from the SEER database, showing a median overall survival of 7.8 years [4]. Surgery plus radiation therapy is estimated to increase the overall median survival time to 9.2 years. Age and treatment modality are significant determinants of patients' survival [3]. Younger patients (aged $<40$ years) survive longer compared with older patients (10-year relative survival of $68 \%$ vs. $43 \%$ ) [4]. Specifically, age $>50$ years is associated with an increase in mortality rate. The estimated age-standardized 5-year, 10-year, and 20-year survival rates for patients diagnosed between 1973 and 2009 are 72, 48, and 31\%, respectively [4]. Improved survival is seen over time with 5-year survival rates of 48,73 , and $81 \%$ for the $1975-1984$, 1985-1994, and 1995-2004 cohorts, respectively [3]. Primary tumor site has not shown to influence chordoma patients' survival $[5,6]$.

As chordoma patients survive longer, the importance of identifying determinants of health-related quality of life (HRQOL) in guiding comprehensive patient care increases [2]. Chordoma progresses slowly but continuously, affecting multiple vital functions, which results in disability and death. As chordoma progresses, it affects patients' physical, social, and mental wellbeing and increases the need for caregiver support [2]. However, symptom burden and other determinants of HRQOL remain poorly defined in patients with chordoma [2]. Improving HRQOL during and after treatment is a primary endpoint underlying clinical decision-making and the development of optimal treatment regimens for patients with chordoma [7]. A better understanding of the symptom burden and main challenges that chordoma patients and caregivers face will help clinicians and palliative care providers improve the quality of care for chordoma patients.

The number of clinical trials testing different interventions for treating chordoma has significantly increased over the past few years [8]. Currently, three Phase 1, two Phase 2 , and one Phase 3 randomized clinical trials are in progress that assess the efficacy and safety of surgery, radiotherapy, and medical therapy in treating chordoma patients [8]. Patient-reported outcomes (PROs), especially symptom burden and functional status, are increasingly assessed in oncology clinical trials for approval and reimbursement purposes [9]. Although challenges exist for assessing PROs for rare conditions like chordoma, many of the barriers are inherent to studying rare diseases rather than PRO measurement itself, and the common barriers and solutions have been documented [10]. Information about the prevalence of the symptoms and other determinants of HRQOL in patients undergoing treatment for chordoma is essential for planning PRO assessment in a clinical trial. This information supports the identification of the most relevant PRO endpoints and provides preliminary support of the content validity of PRO instruments [11].

This study aims to characterize the symptom burden and challenges to quality of life that chordoma patients and their caregivers experience.

\section{Methods}

\section{Study design and setting}

In this cross-sectional study, we analyzed data from a survey of the chordoma community conducted by the Chordoma Foundation to determine the prevalence of selfreported symptoms experienced by chordoma patients and the chordoma-related life challenges that patients and their caregivers experience. The Chordoma Foundation (CF) is a global non-profit organization whose mission is to improve the lives of those affected by chordoma and lead the search for a cure. In 2014, the CF conducted an internet-based survey of the chordoma community to better define the needs and range of experiences of its constituents. At the time of the survey, the CF's contact database included 950 selfidentified chordoma patients and 3,276 individuals identified as family members or friends of patients. In March 2014 , a link to the survey was emailed to all members of the foundation's database, including both patients and caregivers. The survey was open to respondents until the end of June 2014.

\section{Survey instrument}

The domains of the survey include self-reported symptoms, chordoma-related life challenges, quality of care, and the role of the $\mathrm{CF}$ in serving the chordoma community worldwide. The survey, written in English, contains 35 questions and takes approximately 19 minutes to complete. The $\mathrm{CF}$ developed the survey with input from members of the chordoma patient community, the moderators of the chordoma survivors Facebook group, and physicians who treat chordoma patients. The survey was constructed and administered through Survey Monkey with branching logic directing patients and caregivers to answer questions relevant to their respective experiences with chordoma. The survey questionnaire is available in the electronic supplementary material. 


\section{Statistical analysis}

Due to a very small sample size of children respondents, the study analyses focus on respondents who were 18 years and older. Caregivers were defined as parents, spouse, or family members providing care to a patient with chordoma. The analysis of self-reported symptoms was limited to patient respondents because patients are the most reliable source of information regarding their symptoms [12]. The analysis of chordoma-related life challenges included data from both patient and caregiver respondents. Two separate questions with slightly different response options were included in the survey for patients and caregivers about their experience with challenges that they face as a result of chordoma (patients) and caring for a patient with chordoma (caregivers).

Frequency counts and percentages were calculated to determine the prevalence of self-reported symptoms in the sample. Fisher's exact test was used to compare the prevalence of a wide range of symptoms (Tables $3,4,5$ ) in different subgroups. Associations were calculated between the most common symptoms reported and the following clinical characteristics: location of tumor, disease status, and type of treatment received. The prevalence of chordomarelated symptoms among subgroups with different tumor locations, disease status, and type of treatment received was tabulated. Data were analyzed using Stata software version 12 (StataCorp, College Station, TX), and $\mathrm{p}<0.05$ was considered statistically significant.

\section{Results}

\section{Study population}

Between March and June 2014, 709 participants including chordoma patients (358), their family members (294), and friends and others (57) responded to the online CF community survey (Table 1). Among family members, i.e., parents $(31 \%)$, spouses (36\%), and other family members (33\%), 202 participants identified themselves as a caregiver to a chordoma patient. The majority of the patient respondents were over 45 years $(72 \%)$, male $(56 \%)$, educated beyond high school degree (87\%), and from North America (77\%). Caregivers were predominantly over 45 years $(62 \%)$, female $(66 \%)$, educated beyond high school degree $(86 \%)$, and from North America (74\%). The skull base was the most common tumor location in our patient sample $(40 \%)$ followed by sacrococcygeal tumors (31\%) and mobile spine, i.e., neck, mid back, and lower back (27\%). The majority of patients reported either disease-free status, i.e., no evidence of tumor $(41 \%)$ or stable local disease $(28 \%)$. The majority of patients reported receiving multiple therapies, i.e., a
Table 1 Demographic characteristics of the chordoma patients and caregivers

\begin{tabular}{|c|c|c|c|c|}
\hline \multirow[t]{2}{*}{ Age } & \multicolumn{2}{|c|}{$\begin{array}{l}\text { Patients } \\
(n=358)\end{array}$} & \multicolumn{2}{|c|}{$\begin{array}{l}\text { Caregivers } \\
(n=202)^{\mathrm{a}}\end{array}$} \\
\hline & No & $\%$ & No & $\%$ \\
\hline $18-24$ & 16 & 4 & 12 & 6 \\
\hline $25-34$ & 31 & 9 & 27 & 13 \\
\hline $35-44$ & 54 & 15 & 36 & 18 \\
\hline $45-54$ & 84 & 23 & 41 & 20 \\
\hline $55-64$ & 105 & 29 & 52 & 26 \\
\hline $65-74$ & 52 & 15 & 26 & 13 \\
\hline 74 or older & 15 & 4 & 7 & 3 \\
\hline \multicolumn{5}{|l|}{ Gender } \\
\hline Male & 199 & 56 & 68 & 34 \\
\hline Female & 157 & 44 & 133 & 66 \\
\hline \multicolumn{5}{|l|}{ Education } \\
\hline Some high school or less & 8 & 2 & 8 & 4 \\
\hline High school graduate or GED & 36 & 10 & 19 & 9 \\
\hline Vocational college or some college & 99 & 28 & 35 & 17 \\
\hline College degree & 111 & 31 & 73 & 36 \\
\hline Professional or graduate degree & 103 & 29 & 65 & 32 \\
\hline \multicolumn{5}{|l|}{ Region } \\
\hline North America & 275 & 77 & 149 & 74 \\
\hline Europe & 59 & 16 & 32 & 16 \\
\hline South America & 7 & 2 & 5 & 3 \\
\hline Asia & 8 & 2 & 9 & 5 \\
\hline Australia and New Zealand & 6 & 2 & 5 & 3 \\
\hline Africa & 3 & 1 & 2 & 1.0 \\
\hline \multicolumn{5}{|l|}{ Tumor location } \\
\hline Skull base & 144 & 40 & 97 & 48 \\
\hline Mobile spine & 97 & 27 & 58 & 29 \\
\hline Sacrum or Coccyx & 111 & 31 & 42 & 21 \\
\hline Others $^{\mathrm{b}}$ & 4 & 1 & 5 & 2 \\
\hline \multicolumn{5}{|l|}{ Current status of disease } \\
\hline Disease-free (no evidence of tumor) & 145 & 41 & 38 & 19 \\
\hline Stable local disease & 101 & 28 & 43 & 21 \\
\hline Progressive local disease & 21 & 6 & 23 & 11 \\
\hline Stable metastatic disease & 17 & 5 & 7 & 3 \\
\hline Progressive metastatic disease & 25 & 7 & 17 & 8 \\
\hline Not sure & 28 & 8 & 7 & 3 \\
\hline \multicolumn{5}{|l|}{ Treatment received } \\
\hline Surgery only & 89 & 25 & 25 & 12 \\
\hline Radiotherapy only & 24 & 7 & 8 & 4 \\
\hline Medical therapy only & 3 & 1 & 0 & 0 \\
\hline Multiple treatments & 204 & 57 & 146 & 72 \\
\hline No treatment reported & 10 & 3 & 5 & 2 \\
\hline
\end{tabular}

Not reported: age (patient: 1, caregiver: 1); gender (p: 2, c: 1); education (p: 1, c: 2); tumor location (p: 2, c: 5); current status of disease (p: 21, c: 67); treatment received (p: 28, c: 18)

a Reflects caregivers' demographic characteristics (age, gender, education, and region) and patients' tumor location, current status of the disease, and treatment received reported by their caregiver

b Includes extra-axial, multifocal, or unknown 
combination of surgery, radiotherapy, or medical therapy (57\%) followed by surgery only (25\%) and radiotherapy only (7\%). Table 2 shows the distribution of treatment types based on the anatomic site of chordoma tumor reported by chordoma patients.

\section{Patient-reported symptoms}

The most common symptoms that chordoma patients reported include chronic pain (35\%), depression or severe anxiety $(32 \%)$, chronic fatigue $(31 \%)$, difficulty walking
(28\%), and balance impairment (26\%). The majority of patients in our sample reported experiencing at least one symptom (93\%), while more than $36 \%$ experience 5 or more symptoms as a result of suffering from chordoma. Thirty patients (8\%) did not respond to the question about symptoms.

The majority of self-reported symptoms were significantly associated with the location of tumor (Table 3, last column). Among patients with skull base tumors (40\%), the three most common symptoms were double vision (50\%), depression or severe anxiety (32\%), and chronic sinus

Table 2 Distribution of treatment types based on the anatomic site of chordoma tumor reported by chordoma patients $(n=329)$

\begin{tabular}{|c|c|c|c|c|c|c|}
\hline \multirow[t]{2}{*}{ Tumor location } & \multirow[t]{2}{*}{ All } & \multicolumn{5}{|l|}{ Treatment type } \\
\hline & & Surgery only $(n=88)$ & $\begin{array}{l}\text { Radiotherapy } \\
\text { only }(n=24)\end{array}$ & $\begin{array}{l}\text { Medical treatment } \\
\text { only }(n=3)\end{array}$ & $\begin{array}{l}\text { No treatment } \\
(n=10)\end{array}$ & $\begin{array}{l}\text { Multiple } \\
\text { treatments } \\
(n=204)\end{array}$ \\
\hline Skull base & $134(56 \%)$ & $22(16 \%)$ & $11(8 \%)$ & $0(0 \%)$ & $6(4 \%)$ & $95(71 \%)$ \\
\hline Mobile spine & $91(28 \%)$ & $22(24 \%)$ & $7(8 \%)$ & $1(1 \%)$ & $2(2 \%)$ & $59(65 \%)$ \\
\hline Sacrum or Coccyx & $100(30 \%)$ & $42(42 \%)$ & $6(6 \%)$ & $2(2 \%)$ & $2(2 \%)$ & $48(48 \%)$ \\
\hline Other & $4(1 \%)$ & $2(50 \%)$ & $0(0 \%)$ & $0(0 \%)$ & $0(0 \%)$ & $2(50 \%)$ \\
\hline
\end{tabular}

Fisher's exact test $p=0.004$

${ }^{a}$ At least two treatment types from surgery, radiotherapy, or medical treatment categories

Table 3 Distribution of the patient-reported symptoms associated with chordoma by tumor location

\begin{tabular}{|c|c|c|c|c|c|c|c|}
\hline \multirow[t]{2}{*}{ Symptom } & & \multirow{2}{*}{$\begin{array}{l}\text { All }(n=327) \\
(\%)\end{array}$} & \multicolumn{4}{|c|}{ Chordoma tumor location } & \multirow[b]{2}{*}{ P-value } \\
\hline & & & $\begin{array}{l}\text { Skull base } \\
(n=131)(\%)\end{array}$ & $\begin{array}{l}\text { Mobile spine }^{\mathrm{a}} \\
(n=92)(\%)\end{array}$ & $\begin{array}{l}\text { Sacrum or Coccyx } \\
(n=101)(\%)\end{array}$ & $\begin{array}{l}\text { Other }^{\mathrm{b}} \\
(n=3)(\%)\end{array}$ & \\
\hline Chronic pain & $(n=123)$ & 38 & 14 & 57 & 51 & 33 & 0.001 \\
\hline Depression or severe anxiety & $(n=113)$ & 35 & 35 & 37 & 31 & 67 & 0.489 \\
\hline Chronic fatigue & $(n=110)$ & 34 & 30 & 39 & 33 & 67 & 0.269 \\
\hline Difficulty walking & $(n=100)$ & 31 & 7 & 40 & 54 & 67 & 0.001 \\
\hline Balance impairment & $(n=94)$ & 29 & 33 & 26 & 25 & 67 & 0.205 \\
\hline Difficulty sitting & $(n=85)$ & 26 & 2 & 20 & 62 & 33 & 0.001 \\
\hline Double vision & $(n=76)$ & 23 & 56 & 1 & 2 & 0 & 0.001 \\
\hline Sexual dysfunction & $(n=74)$ & 23 & 15 & 10 & 46 & 0 & 0.001 \\
\hline Limited mobility & $(n=63)$ & 19 & 3 & 33 & 29 & 0 & 0.001 \\
\hline Urinary incontinence & $(n=52)$ & 16 & 2 & 2 & 48 & 0 & 0.001 \\
\hline Chronic sinus problems & $(n=46)$ & 14 & 34 & 1 & 0 & 0 & 0.001 \\
\hline Urinary retention & $(n=46)$ & 14 & 1 & 3 & 42 & 0 & 0.001 \\
\hline Hearing loss & $(n=44)$ & 13 & 32 & 1 & 1 & 0 & 0.001 \\
\hline Fecal incontinence & $(n=41)$ & 13 & 0 & 1 & 40 & 0 & 0.001 \\
\hline Bowel obstruction & $(n=38)$ & 12 & 2 & 7 & 30 & 0 & 0.001 \\
\hline Other vision problems & $(n=28)$ & 9 & 16 & 3 & 4 & 0 & 0.002 \\
\hline
\end{tabular}

Symptoms were asked using the following survey question: "Which of the following health effects have you ever suffered as a result of chordoma?"

${ }^{\text {a }}$ Includes neck, mid back, and lower back

${ }^{\mathrm{b}}$ Includes extra-axial, multifocal, or unknown

${ }^{\mathrm{c}} \mathrm{P}$-values were calculated using Fisher's exact test 
problems (31\%). Among patients with sacral tumors (20\%), difficulty sitting (55\%), difficulty walking (53\%), and sexual dysfunction (49\%) were the most common, and among patients with lower back tumor (11\%), the most common symptoms were chronic pain (54\%), difficulty walking (49\%), and limited mobility (41\%). Several common symptoms were significantly different in their prevalence across different types of treatment received and disease status (Tables 4, 5).

\section{Challenges experienced by chordoma patients and caregivers}

Table 6 reports the prevalence of challenges that patients and caregivers experienced as a result of chordoma in the following domains: emotional health and coping; employment and finances, access to care and information; and quality of care. Eight patients (2\%) and four caregivers (2\%) did not respond to the question about challenges faced as a result of suffering from chordoma. The most common challenges reported by patients were delayed care (37\%), long-term disability (33\%), confusion or unanswered questions about chordoma (28\%), difficulty finding experienced physicians or treatment centers (27\%), misdiagnosis (24\%), and short-term disability (24\%). Among caregivers, the most frequently reported challenges included grief (55\%), delayed care (47\%), difficulty helping the patient cope with his/her illness (45\%), confusion or unanswered questions about chordoma (45\%), difficulty finding experienced physicians or treatment centers (43\%), and misdiagnosis of the patient (28\%).

\section{Discussion}

Although several studies of chordoma symptoms and quality of life exist, they focus on a small number of cases, limited list of symptoms, or a specific tumor location or treatment modality $[2,7,13,14]$. This study adds to the existing literature by investigating self-reported symptom burden and life challenges among a large group of chordoma patients and caregivers across different tumor characteristics. Our study data suggest high symptom burden among chordoma patients that varies based on the location of the tumor, disease status, and type of treatment received. In addition, our findings show that the chordoma patients and caregivers face many medical, emotional, and healthcare challenges. Receiving inappropriate care including but not limited to delayed diagnosis or misdiagnosis and difficulty finding experienced physicians or medical centers were among the most commonly cited challenges. Our study results provide a better understanding of the challenges

Table 4 Distribution of the patient-reported symptoms associated with chordoma by treatment received

\begin{tabular}{|c|c|c|c|c|c|c|c|c|}
\hline \multirow[t]{2}{*}{ Symptom } & & \multirow{2}{*}{$\begin{array}{l}\text { All } \\
(n=322) \\
(\%)\end{array}$} & \multicolumn{5}{|c|}{ Treatment received } & \multirow[t]{2}{*}{ P-value ${ }^{a}$} \\
\hline & & & $\begin{array}{l}\text { Surgery only } \\
(n=87)(\%)\end{array}$ & $\begin{array}{l}\text { Radiotherapy } \\
\text { only }(\mathrm{n}=22) \\
(\%)\end{array}$ & $\begin{array}{l}\text { Medical therapy } \\
\text { only }(n=3)(\%)\end{array}$ & $\begin{array}{l}\text { No treat- } \\
\text { ment }(n=8) \\
(\%)\end{array}$ & $\begin{array}{l}\text { Multiple ther- } \\
\text { apy }(n=202) \\
(\%)\end{array}$ & \\
\hline Chronic pain & $(n=122)$ & 38 & 49 & 27 & 33 & 38 & 34 & 0.107 \\
\hline Depression or severe anxiety & $(n=111)$ & 34 & 38 & 27 & 67 & 38 & 33 & 0.632 \\
\hline Chronic fatigue & $(n=106)$ & 33 & 29 & 18 & 33 & 38 & 36 & 0.375 \\
\hline Difficulty walking & $(n=97)$ & 30 & 34 & 27 & 33 & 50 & 28 & 0.502 \\
\hline Balance impairment & $(n=92)$ & 29 & 22 & 23 & 33 & 38 & 32 & 0.394 \\
\hline Difficulty sitting & $(n=82)$ & 25 & 44 & 18 & 33 & 50 & 17 & 0.001 \\
\hline Double vision & $(n=75)$ & 23 & 13 & 32 & 33 & 25 & 27 & 0.046 \\
\hline Sexual dysfunction & $(n=72)$ & 22 & 26 & 27 & 33 & 13 & 20 & 0.607 \\
\hline Limited mobility & $(n=62)$ & 19 & 26 & 5 & 67 & 25 & 17 & 0.020 \\
\hline Urinary incontinence & $(n=49)$ & 15 & 15 & 9 & 67 & 38 & 14 & 0.059 \\
\hline Urinary retention & $(n=46)$ & 14 & 16 & 0 & 33 & 38 & 14 & 0.040 \\
\hline Chronic sinus problems & $(n=45)$ & 14 & 5 & 18 & 0 & 13 & 18 & 0.022 \\
\hline Hearing loss & $(n=44)$ & 14 & 6 & 18 & 33 & 13 & 16 & 0.050 \\
\hline Fecal incontinence & $(n=40)$ & 12 & 18 & 14 & 33 & 13 & 9 & 0.128 \\
\hline Bowel obstruction & $(n=38)$ & 12 & 15 & 9 & 67 & 13 & 10 & 0.075 \\
\hline Other vision problems & $(n=25)$ & 8 & 3 & 14 & 33 & 13 & 8 & 0.084 \\
\hline
\end{tabular}

Symptoms were asked using the following survey question: "Which of the following health effects have you (the patient) ever suffered as a result of chordoma?"

${ }^{\text {a }} \mathrm{P}$-values were calculated using Fisher's exact test 
Table 5 Distribution of the patient-reported symptoms associated with chordoma by disease status $(n=309)$

\begin{tabular}{|c|c|c|c|c|c|c|c|c|c|}
\hline \multirow[t]{2}{*}{ Symptom } & & \multirow{2}{*}{$\begin{array}{l}\text { All } \\
(n=309) \\
(\%)\end{array}$} & \multicolumn{6}{|c|}{ Current disease status } & \multirow[t]{2}{*}{ P-value } \\
\hline & & & $\begin{array}{l}\text { Disease-free } \\
(n=138)(\%)\end{array}$ & $\begin{array}{l}\text { Stable local } \\
(n=87)(\%)\end{array}$ & $\begin{array}{l}\text { Progressive } \\
\text { local }(n=18) \\
(\%)\end{array}$ & $\begin{array}{l}\text { Stable meta- } \\
\text { static }(n=17) \\
(\%)\end{array}$ & $\begin{array}{l}\text { Progressive } \\
\text { metastatic } \\
(n=24)(\%)\end{array}$ & $\begin{array}{l}\text { Not sure } \\
(n=25) \\
(\%)\end{array}$ & \\
\hline Chronic pain & $(n=117)$ & 38 & 39 & 29 & 44 & 41 & 58 & 36 & 0.157 \\
\hline $\begin{array}{l}\text { Depression or } \\
\text { severe anxiety }\end{array}$ & $(n=112)$ & 36 & 37 & 37 & 39 & 35 & 33 & 32 & 0.997 \\
\hline Chronic fatigue & $(n=103)$ & 33 & 30 & 38 & 17 & 35 & 50 & 28 & 0.233 \\
\hline Difficulty walking & $(n=92)$ & 30 & 30 & 16 & 56 & 35 & 58 & 24 & 0.001 \\
\hline $\begin{array}{l}\text { Balance impair- } \\
\text { ment }\end{array}$ & $(n=90)$ & 29 & 22 & 34 & 33 & 29 & 38 & 36 & 0.290 \\
\hline Difficulty sitting & $(n=76)$ & 25 & 33 & 11 & 28 & 12 & 50 & 8 & 0.001 \\
\hline Double vision & $(n=72)$ & 23 & 17 & 39 & 28 & 12 & 17 & 16 & 0.004 \\
\hline Sexual dysfunction & $(n=72)$ & 23 & 22 & 14 & 33 & 53 & 38 & 20 & 0.006 \\
\hline Limited mobility & $(n=62)$ & 20 & 22 & 8 & 28 & 35 & 42 & 12 & 0.001 \\
\hline $\begin{array}{l}\text { Urinary inconti- } \\
\text { nence }\end{array}$ & $(n=48)$ & 16 & 20 & 4 & 17 & 12 & 38 & 12 & 0.001 \\
\hline $\begin{array}{l}\text { Chronic sinus } \\
\text { problems }\end{array}$ & $(n=44)$ & 14 & 9 & 26 & 11 & 18 & 8 & 8 & 0.009 \\
\hline Urinary retention & $(n=43)$ & 14 & 20 & 6 & 6 & 18 & 17 & 12 & 0.051 \\
\hline Hearing loss & $(n=41)$ & 13 & 6 & 23 & 17 & 18 & 13 & 16 & 0.005 \\
\hline Fecal incontinence & $(n=39)$ & 13 & 17 & 4 & 17 & 12 & 21 & 12 & 0.021 \\
\hline Bowel obstruction & $(n=36)$ & 12 & 12 & 5 & 22 & 18 & 29 & 8 & 0.010 \\
\hline $\begin{array}{l}\text { Other vision prob- } \\
\text { lems }\end{array}$ & $(n=27)$ & 9 & 4 & 18 & 17 & 6 & 4 & 0 & 0.003 \\
\hline
\end{tabular}

Symptoms were asked using the following survey question: "Which of the following health effects have you (the patient) ever suffered as a result of chordoma?"

${ }^{a}$ P-values were calculated using Fisher's exact test

associated with chordoma, with the aim of helping improve the quality of care provided to chordoma patients.

Our study also provides prevalence data for a comprehensive list of patient-reported symptoms as well as patient- and caregiver-reported life challenges associated with chordoma. These findings can inform the design of clinical trials and guide the development of chordomaspecific PRO instruments or selection of existing generic instruments. Information about the prevalence of symptoms and life challenges is necessary for identifying which concepts should be assessed. For detailed information about symptoms and life challenges specific to sacral chordoma patients and an example of using existing generic (nondisease specific) PRO instruments to develop a comprehensive questionnaire, see van Wulfften Palthe et al. (2016) [14]. Because of the nature of the chordoma-in that the impact of the disease varies by the location of the tumor(s), instruments for specific types of chordoma may be warranted, depending on the goals of the study. This could be operationalized as a series of independent tumor site-specific instruments or one instrument with tumor site-specific modules and branching logic. Further, our findings can be directly utilized in clinical practice. Information about prevalent symptoms and challenges faced by patients and caregivers may help improve patient-provider communication, inform decision-making, healthcare management, and ultimately improve health outcomes.

The major strengths of this study include its relatively large sample size of both chordoma patients and caregivers. Given the incidence and average survival of chordoma patients, the estimated prevalence is approximately 6 per million, or roughly 2,000 patients in the United States. Thus, the survey sample included more than $10 \%$ of the estimated United States chordoma patient population. In addition, the construction of the survey was patient-centered, and approximately $90 \%$ of respondents completed the entire questionnaire. However, we acknowledge the limitations associated with the online questionnaire administration. Our study sample included a high proportion of respondents with a university degree (65\%), and was limited to those who have access to a computer, can read in English, and have the mental and physical capacity to complete the online questionnaire. In addition, because patients and their caregivers had access to the survey questionnaire, 
Table 6 Challenges that patients/caregivers face as a result of having/caring for a patient with chordoma

\begin{tabular}{|c|c|c|c|c|}
\hline & \multicolumn{2}{|c|}{$\begin{array}{l}\text { Patients } \\
(n=358)\end{array}$} & \multicolumn{2}{|c|}{$\begin{array}{l}\text { Caregivers } \\
(n=202)\end{array}$} \\
\hline & No. & Percent & No. & Percent \\
\hline \multicolumn{5}{|l|}{ Emotional health and coping } \\
\hline Feelings of loneliness or isolation & 104 & 29 & 87 & 43 \\
\hline Difficulty coping/helping the patient cope with his/her illness & 93 & 26 & 91 & 45 \\
\hline Grief $^{\mathrm{a}}$ & - & - & 111 & 55 \\
\hline Family conflict & 34 & 10 & 46 & 23 \\
\hline Difficulty helping children or other family members cope & 47 & 13 & 67 & 33 \\
\hline Difficulty talking about chordoma and how it has affected my life & 64 & 18 & 43 & 21 \\
\hline \multicolumn{5}{|l|}{ Employment and finances } \\
\hline Change in career or reduced ability to work & 118 & 33 & 63 & 31 \\
\hline Short-term disability ${ }^{\mathrm{b}}$ & 84 & 24 & - & - \\
\hline Long-term disability ${ }^{\mathrm{b}}$ & 119 & 33 & - & - \\
\hline Loss of employment & 74 & 21 & 20 & 10 \\
\hline Financial distress (including bankruptcy or foreclosure) & 59 & 17 & 39 & 19 \\
\hline \multicolumn{5}{|l|}{ Access to care and information } \\
\hline Denial of insurance coverage for the patient's recommended treatment & 45 & 13 & 34 & 17 \\
\hline Loss of health insurance ${ }^{b}$ & 20 & 6 & - & - \\
\hline Inability to pay for the patient's recommended treatment & 28 & 8 & 20 & 10 \\
\hline Inability to pay for travel, lodging, or other treatment-related expenses & 45 & 13 & 28 & 14 \\
\hline Confusion or unanswered questions about chordoma & 101 & 28 & 90 & 45 \\
\hline Difficulty finding experienced physicians or treatment centers & 96 & 27 & 86 & 43 \\
\hline \multicolumn{5}{|l|}{ Quality of care } \\
\hline Delayed diagnosis of patient & 134 & 37 & 95 & 47 \\
\hline Misdiagnosis of patient & 85 & 24 & 56 & 28 \\
\hline Difficulty dealing with physicians or medical staff & 77 & 22 & 50 & 25 \\
\hline Patient received wrong or inappropriate care & 64 & 18 & 49 & 24 \\
\hline
\end{tabular}

The challenges were asked in the following questions in the survey: "Which of the following challenges have you faced as a result of your experience with chordoma?" and "Which of the following challenges have you faced in caring for someone with chordoma?"

${ }^{a}$ Response option only available to respondents who identify themselves as caregivers of chordoma patients

${ }^{\mathrm{b}}$ Response option only available to respondents who identify themselves as patients for questions that could be answered both by patients and caregivers, it is possible that some responses are counted both from a patient and his or her caregiver. Nonetheless, the distribution of age and tumor location in our sample is similar to that reported in the literature from the representative population-based estimates [1-3]. Although this survey included a large proportion $(10 \%)$ of the US chordoma patient population, because of the sampling scheme that was employed in this study, the denominator is not clearly defined and the sample underrepresents population subgroups who may experience the challenges of chordoma differently. Therefore, the results of this study are limited preliminary estimates intended to be hypothesis generating and to inform future research.

Previous studies have estimated quality of life in specific subgroups of chordoma patients using validated, non-disease specific instruments, such as the 36-Item Short Form
Health Survey (SF-36) and the European Organization for Research and Treatment of Cancer Quality of Life Core 30 (EORTC QLQ-C30) [2, 13]. However, the intent of the CF survey was not to estimate the quality of life scores for the study sample. Instead, the survey questionnaire was designed to document the prevalence of a wide range of symptoms and challenges experienced by chordoma patients and caregivers. The content was determined based on input from members of the chordoma patient community, the moderators of the chordoma survivors Facebook group, and physicians who treat chordoma patients, and the questionnaire included open-ended response fields for each response option of "other" to elicit any additional symptoms and issues. The CF survey was able to capture symptoms and challenges specific to chordoma that were not reflected in the more general quality of life measures used previously. 


\section{Conclusion}

Our study findings suggest a high symptom burden among patients with chordoma. In addition, many patients and caregivers are facing challenges related to access and quality of care and psychological health. This study provides preliminary, limited estimates of the prevalence of a wide range of self-reported symptoms and challenges that will inform the assessment of patient-reported outcomes in future clinical trials and will help clinicians and palliative care providers better understand and manage symptoms of chordoma patients.

\section{Compliance with ethical standards}

Conflict of interest Paula H. Song serves on the board of the Chordoma Foundation. Josh Sommer is the executive director of the Chordoma Foundation. Hadi Beyhaghi has no conflict of interest relevant to this manuscript. Antonia V. Bennett has no conflict of interest relevant to this manuscript.

Ethical approval This article does not contain any studies with human participants performed by any of the authors. The authors analyzed data from the Chordoma Foundation community survey. The authors also sought IRB approval early on, and the study was determined to be exempt.

Open Access This article is distributed under the terms of the Creative Commons Attribution 4.0 International License (http:// creativecommons.org/licenses/by/4.0/), which permits unrestricted use, distribution, and reproduction in any medium, provided you give appropriate credit to the original author(s) and the source, provide a link to the Creative Commons license, and indicate if changes were made.

\section{References}

1. Walcott, B. P., Nahed, B. V., Mohyeldin, A., Coumans, J. V., Kahle, K. T., \& Ferreira, M. J. (2012). Chordoma: Current concepts, management, and future directions. The Lancet Oncology, 13(2), e69-e76.

2. Diaz, R. J., Maggacis, N., Zhang, S., \& Cusimano, M. D. (2014). Determinants of quality of life in patients with skull base chordoma: Clinical article. Journal of Neurosurgery, 120(2), 528-537.

3. Chambers, K. J., Lin, D. T., Meier, J., Remenschneider, A., Herr, M., \& Gray, S. T. (2014). Incidence and survival patterns of cranial chordoma in the United States. The Laryngoscope, 124(5), 1097-1102.

4. Smoll, N. R., Gautschi, O. P., Radovanovic, I., Schaller, K., \& Weber, D. C. (2013). Incidence and relative survival of chordomas. Cancer, 119(11), 2029-2037.

5. McMaster, M. L., Goldstein, A. M., Bromley, C. M., Ishibe, N., \& Parry, D. M. (2001). Chordoma: Incidence and survival patterns in the United States, 1973-1995. Cancer Causes \& Control, 12(1), 1-11.

6. Lee, J., Bhatia, N. N., Hoang, B. H., Ziogas, A., \& Zell, J. A. (2012). Analysis of prognostic factors for patients with chordoma with use of the California Cancer Registry. The Journal of Bone and Joint Surgery. American volume, 94(4), 356-363.

7. Gil, Z., \& Fliss, D. M. (2010). Quality of life in patients with skull base tumors: current status and future challenges. Skull Base, 20(01), 011-018.

8. Stacchiotti, S., \& Sommer, J. (2015). Building a global consensus approach to chordoma: A position paper from the medical and patient community. The Lancet Oncology, 16(2), e71-e83.

9. Gnanasakthy, A., DeMuro, C., Clark, M., Haydysch, E., Ma, E., \& Bonthapally, V. (2016). patient-reported outcomes labeling for products approved by the Office of Hematology and Oncology Products of the US Food and Drug Administration (2010-2014). Journal of Clinical Oncology, 34, 1928-1934.

10. Basch, E., \& Bennett, A. V. (2014). Patient-reported outcomes in clinical trials of rare diseases. Journal of General Internal Medicine, 29(3), 801-803.

11. Food and Drug Administration (2009). Guidance for industry: patient-reported outcome measures: use in medical product development to support labeling claims. Federal Register, 74, 65132-65133.

12. Sneeuw, K. C., Sprangers, M. A., \& Aaronson, N. K. (2002). The role of health care providers and significant others in evaluating the quality of life of patients with chronic disease. Journal of Clinical Epidemiology, 55(11), 1130-1143.

13. Srivastava, A., Vischioni, B., Fiore, M. R., Vitolo, V., Fossati, P., Iannalfi, A., ... \& Orecchia, R. (2013). Quality of life in patients with chordomas/chondrosarcomas during treatment with proton beam therapy. Journal of Radiation Research, 54(suppl 1), i43-i48.

14. van Wulfften Palthe, O. D., Janssen, S. J., Wunder, J. S., Ferguson, P. C., Wei, G., Rose, P. S., ... \& Hornicek, F. J., et al. (2016). What questionnaires to use when measuring quality of life in sacral tumor patients: The updated sacral tumor survey. The Spine Journal. 